\title{
Staphylococcus epidermidis Isolated From Newborn Infants Express Pilus-Like Structures and Are Inhibited by the Cathelicidin-Derived Antimicrobial Peptide LL37
}

\author{
ANNIKA NELSON, KJELL HULTENBY, ÉVA HELL, HILDE M. RIEDEL, HJALMAR BRISMAR, JAN-INGMAR FLOCK, \\ JOACHIM LUNDAHL, CHRISTIAN G. GISKE, AND GIOVANNA MARCHINI
}

Departments of Woman and Child Health [A.N., E.H., G.M.], Clinical Microbiology [H.M.R., J.-I.F., C.G.G.], and Medicine [J.L.], Karolinska Institutet, Stockholm 17176, Sweden; Department of Laboratory Medicine [K.H.], Karolinska Institutet, Stockholm 14186, Sweden; Department of Cell Physics [H.B.], Royal Institute of Technology, Stockholm 10691, Sweden

\begin{abstract}
Coagulase-negative staphylococci and its subtype Staphylococcus epidermidis are major indigenous Gram-positive inhabitants of the human skin. Colonization occurs in direct connection with birth and terrestrial adaptation. This study focuses on factors that may influence skin colonization of the newborn infant that relates to the immune status of both the bacteria and the host. Skin is an effective barrier against bacteria, and this function is partly mediated by the presence of antimicrobial peptides including human cathelicidin peptide LL37. Gram-positive bacteria have been described to have adhesive pili on their surface that mediates specific attachment to the host. Here, we identify, by negative staining transmission electron microscopy (EM), two different types of piluslike structures commonly expressed on S. epidermidis isolated from newborn infants. We also show that the cathelicidin antimicrobial peptide LL37, constitutively expressed in the skin barrier of the newborn, significantly inhibited growth of $S$. epidermidis indicating its importance for the ecological stability of the skin microbiota. Further studies are required to elucidate molecular mechanisms of host-microbe interactions, both for the maintenance of a mutually beneficial homeostatic relationship and for the protection of self when it results in overt disease. (Pediatr Res 66: 174-178, 2009)
\end{abstract}

$\mathrm{C}$ oagulase-negative staphylococci (CoNS) are major skin commensals in humans (1). Within the first few hours of life colonization occurs (2), and by $1 \mathrm{~d}$ of age $84 \%$ of all healthy neonates have their skin colonized (3). Among the CoNS, particular attention has been focused on Staphylococcus epidermidis because it is the most common species responsible for infection causing significant morbidity, mortality, and incurring healthcare costs worldwide (4). In neonates, CoNS have emerged as prevalent and important pathogens, responsible for approximately $50 \%$ of all episodes of lateonset $(>72 \mathrm{~h})$ sepsis in very low birth weight infants (5). Recent evidence also links these bacteria to the pathogenesis of the immunologic skin reaction erythema toxicum, frequently seen in healthy newborns (3).

Received February 5, 2009; accepted March 25, 2009

Correspondence: Giovanna Marchini, M.D., Ph.D., Neonatal Unit at Astrid Lindgren Children's Hospital, FRH-lab, C4:U1, Karolinska University Hospital Solna, 17176 Stockholm, Sweden; e-mail: giovanna.marchini@karolinska.se

Supported by Frimurarbarnhuset Stockholm, Sällskapet Barnavård, Stiftelsen Samariten, and Crown Princess Lovisa Memory Foundation.
Ecological stability of the commensal microflora is partly maintained by interactions with its human host. Our knowledge of how commensal bacteria interact with their host or how they communicate with each other is limited. We know that at birth commensals have to face the antimicrobial defense mechanisms of the skin and the vernix caseosa, a cream-like coating on newborns secreted by the fetal sebaceous glands. Human antimicrobial cathelicidin peptide LL37 is present in both vernix caseosa and the skin already at the time of birth, and the peptide is also up-regulated in the erythema toxicum lesions of the newborn infant (6). The presence of LL37 offers increased protection against bacterial infections in mice and humans $(7,8)$. Thus, we hypothesized that LL37 is of importance for the microbial milieu of the skin, and we tested if it could influence growth of $S$. epidermidis strains isolated from newborn infants.

Recent investigations have described that $S$. epidermidis express pilus-like or fibrillar structures protruding from the cell surface (9-12). Pili are polymeric, hydrophobic, proteinaceous structures that may be involved in many functions such as specific host recognition and attachment, invasion, and biofilm formation $(13,14)$. In previous studies on S. epidermidis, only one strain isolated from blood and two commercially available laboratory strains have been analyzed for possible pili expression in humans. Another aim of this study was, therefore, to visualize the prevalence and appearance of these surface structures in S. epidermidis strains isolated from the skin of healthy newborns. Infants with the rash of erythema toxicum or sepsis were also studied.

The major virulence factor of CoNS is ascribed to the formation of biofilm $(15,16)$, but proteinaceous surface components, such as fibrinogen-binding protein (Fbe; 17-19) and accumulation-associated protein (Aap; 20), play major roles in the adherence of $S$. epidermidis to implanted biomaterials and accumulative growth on polymer surfaces. Our last aim was to search for a hypothesized link between the expression of pili

Abbreviations: Aap, accumulation-associated protein; BHI, brain-heart infusion; CI, clinical isolate; CoNS, coagulase-negative staphylococci; EM, electron microscopy; Fbe, fibrinogen-binding protein; MHB, Mueller Hinton broth; MIC, minimal inhibitory concentration 
and the production of biofilm and bacterial surface proteins Aap and Fbe, respectively.

\section{MATERIALS AND METHODS}

Patients. The ethics committee of Karolinska University Hospital approved the study, and parents gave their informed consent to participate. Except for one preterm infant with CoNS sepsis, all pregnancies and deliveries were at term gestation and uncomplicated (GA $40 \pm 1$ wk; mean \pm SD). There were 11 boys and 10 girls with birth weight $3735 \pm 582 \mathrm{~g}$ (mean \pm $\mathrm{SD})$. All infants had an uneventful neonatal period and were exclusively breastfed on demand. No antimicrobial therapy was given to any mother or their offspring, and infants were delivered within $24 \mathrm{~h}$ after rupture of the membranes. Amniotic fluid was clear in all cases. Infants were 1 -d old $(1 \pm$ $0.3 \mathrm{~d}$; mean $\pm \mathrm{SD}$ ) at the time of sample collection, and none of the infants were bathed or had been outside the hospital. One biopsy was taken from an erythema toxicum lesion of a healthy 1-d-old infant, as previously described (3).

Bacterial strains. Skin swabs for microbial cultures were collected according to hospital routine from normal skin surface $(n=9)$ and from regions with erythema toxicum $(n=12)$, but never from the region covered by the diaper. We isolated CoNS in 17 infants, and by using the API STAPH V4.0 identification system (BioMérieux, Marcy l-Etoile, France), we identified 16 of these strains as $S$. epidermidis.

A total number of $13 \mathrm{~S}$. epidermidis strains were chosen randomly for further investigation. Eight from normal skin (clinical isolate, CI-1-8), four from erythema toxicum lesions (CI-9-12), and one blood isolate obtained from a preterm infant (CI-13) with clinical manifestations of sepsis were studied. As reference strains, we included S. epidermidis ATCC 35984, S. epidermidis ATCC 12228, Staphylococcus aureus ATCC 29213, and Escherichia coli ATCC 25922.

Determination of minimal inhibitory concentration for LL37. Antimicrobial susceptibility of S. epidermidis (CI-1-13; ATCC 12228; ATCC 35984; ATCC 29213; ATCC 25922) was performed with the microdilution broth method according to the recommendations of the Clinical and Laboratory Standards Institute (CLSI; 21). Refined Mueller Hinton broth (MHB; BD Diagnostic systems, NJ) was used as described earlier, because standard MHB has been found to underestimate the activity of antimicrobial peptides $(22,23)$. Becasue $S$. epidermidis were unable to grow in refined MHB, a 1:1 mixture of regular MHB and refined MHB was used for the experiments. A stock solution of peptide LL37 (Innovagen, Lund, Sweden) was prepared by adding the peptide to refined MHB containing $0.05 \%$ acetic acid to prevent precipitation of the peptide. A $0.5 \mathrm{McF}$ arland standard inoculum, corresponding to approximately $10^{8}$ colony forming units (CFU) per $\mathrm{mL}$, was obtained by suspending bacterial colonies in PBS. A 1:10 dilution was made from this suspension and $5 \mu \mathrm{L}$ of this solution was suspended in microtiter plates containing $100 \mu \mathrm{L}$ of refined MHB supplemented with LL37, corresponding to a final suspension of $5 \times 10^{4} \mathrm{CFU}$ per well. The wells in the microtiter plate contained LL37 in concentrations ranging from 0.25 to $256 \mathrm{mg} \cdot \mathrm{L}^{-1}$ (2-fold dilutions). Minimal inhibitory concentration (MIC) was recorded as the lowest concentration completely inhibiting growth, as recorded by the unaided eye. Wells containing refined MHB without LL37 were used for growth control. The microtiter plates were read after an 18 -h incubation at $35^{\circ} \mathrm{C}$.

Transmission electron microscopy. S. epidermidis surface structures were visualized by negative staining transmission electron microscopy (EM), in which bacteria (CI-1-13; ATCC 12228; ATCC 35984) were grown on blood agar plates for $36-48 \mathrm{~h}$ or in brain-heart infusion (BHI) broth (BD Diagnostic systems, NJ) from a starting point of $\mathrm{OD}_{600} 0.05$ until mid-log phase. Colonies grown on agar plates were resuspended in $1 \%$ paraformaldehyde solution, whereas liquid cultures were centrifuged at $1500 \times \mathrm{g}$ for $3 \mathrm{~min}$ and then resuspended in $4 \%$ paraformaldehyde solution for $15 \mathrm{~min}$. This was followed by two cycles of centrifugation and resuspension in PBS. An aliquot of $4 \mu \mathrm{L}$ was added to a grid coated with a Formvar supporting film coated with carbon for $5 \mathrm{~min}$. The excess solution was soaked off by a filter paper, and the grid was stained with $0.5 \%$ uranyl acetate in water for 5 min and air-dried. Samples were visualized in a Tecnai FEI 10 electron microscope at $80 \mathrm{kV}$. Transmission EM analysis was always done immediately after fixation of bacteria.

In addition, S. epidermidis (CI-9) was incubated for $1 \mathrm{~h}$ at $37^{\circ} \mathrm{C}$ with 2 $\mathrm{mg} \cdot \mathrm{mL}^{-1}$ proteinase K (Sigma-Aldrich Chemical Co., St. Louis, MO) or 30 $\mu \mathrm{g} \cdot \mathrm{mL}^{-1}$ DNase (RQ1, Promega, Madison, WI), after treatment as previously described. Results were analyzed by negative staining.

Immunogold EM. To visualize the binding sites of Fbe on bacterial surface, immunogold EM was performed on S. epidermidis (CI-9-12). Bacteria were grown as previously described, and $4 \mu \mathrm{L}$ of bacterial sample was added to Formvar-coated nickel grids for $5 \mathrm{~min}$. To minimize nonspecific labeling, grids were incubated in $1 \% \mathrm{BSA}$ and $1 \%$ gelatin, followed by incubation with sheep polyclonal anti-Fbe (Jan-Ingmar Flock, Karolinska Institutet, Sweden), and diluted 1:10. After rinsing, secondary goldconjugated antibodies at 1:50 (donkey anti-sheep IgG, 5-nm gold particles) were added. Finally, grids were stained for $15 \mathrm{~s}$ with aqueous uranyl acetate and processed in a Tecnai FEI 10 electron microscope at $80 \mathrm{kV}$.

Isolation of genomic DNA. Genomic DNA was prepared using a QIAmp DNA minikit (Qiagen, Hilden, Germany) as directed by the manufacturer, with the modification that cells were incubated at $37^{\circ} \mathrm{C}$ for $1 \mathrm{~h}$ with 200 $\mu \mathrm{g} \cdot \mathrm{mL}^{-1}$ lysostaphin (Sigma-Aldrich Chemical Co., St. Louis, MO) before the lysis step; after 1 h, $20 \mu \mathrm{L}$ proteinase K (Qiagen, Hilden, Germany) was added to the cells, and the culture was incubated at $56^{\circ} \mathrm{C}$ for $30 \mathrm{~min}$ and then $95^{\circ} \mathrm{C}$ for $15 \mathrm{~min}$ to lyse the cells.

PCR amplification of the aap gene. The PCR assays used in this study to detect the presence of the aap gene in S. epidermidis (CI-I-13; ATCC 35984; ATCC 12228) were performed by amplifying two different fragments of aap using two primer pairs that amplified nucleotides 1140-1772 (primers aap-1 and aap-2) and 7023-7172 (primers aap-3 and aap-4) (Table 1). The PCR reactions contained $10 \mu \mathrm{L}$ of the extracted DNA, $1 \times$ PCR buffer II (Applied Biosystems, Foster City, CA), $3 \mathrm{mM} \mathrm{MgCl}$ (Applied Biosystems, Foster City, CA), $0.2 \mathrm{mM}$ dNTP (Applied Biosystems, Foster City, CA), $0.2 \mu \mathrm{M}$ of each primer, and $1.25 \mathrm{U}$ of AmpliTaq Gold DNA Polymerase (Applied Biosystems, Foster City, CA), as well as water added to a final volume of 50 $\mu$ L. A positive control (genomic DNA of S. epidermidis ATCC 35984) and a negative control (reaction mixture without DNA) were included in each PCR run. The PCR assays were performed on a PTC-200 Peltier thermal cycler (MJ Research Inc., Scandinavian Diagnostics Services, Falkenberg, Sweden), and the following conditions were used: an initial denaturation step at $95^{\circ} \mathrm{C}$ for $12 \mathrm{~min}$, followed by 30 cycles of amplification, $\left(95^{\circ} \mathrm{C}, 30 \mathrm{~s} ; 58^{\circ} \mathrm{C}, 30 \mathrm{~s}\right.$; and $72^{\circ} \mathrm{C}, 60 \mathrm{~s}$ ), and a final extension step at $72^{\circ} \mathrm{C}$ for $7 \mathrm{~min}$. Electrophoresis was performed on the PCR products using a $2 \%$ E-Gel precast agarose gel containing ethidium bromide (Invitrogen, Carlsbad, CA), and the products were identified by UV illumination.

Finally, the PCR products were purified with a JETquick PCR Purification Spin Kit (Genomed GmbH, Bad Oeynhausen, Germany) and sequenced on both strands using BigDye Terminator v3.1 Cycle Sequencing Kit (Applied Biosystems, Foster City, CA), with primers aap-1, aap-2, aap-3, and aap-4. Reaction products were analyzed using an Applied Biosystems 3730 DNA Analyzer (MMK, Karolinska University Hospital, Stockholm, Sweden). The resulting chromatograms were analyzed using Applied Biosystem Sequence Scanner v1.0, and the DNA sequences were then used for database searching using the BLAST function on the NCBI database (www.ncbi.nlm.nih.gov) to identify the reaction products.

Determination of biofilm formation. Biofilm formation was determined by the ability of cells to adhere to the wells of a microtiter plate. $S$. epidermidis (CI-1-13, ATCC 12228, ATCC 35984) were grown overnight in BHI broth after which $200 \mu \mathrm{L}$ of culture, diluted in BHI broth to $0.05 \mathrm{OD}_{600}$, was added to each well of a 96-well polystyrene microtiter plate (Corning Incorporated Life Sciences, Lowell, MA). A negative control of BHI broth without bacteria was included, and each experiment was performed in five replicate wells. After incubation at $37^{\circ} \mathrm{C}$ for $20 \mathrm{~h}$, each well was washed twice with $200 \mu \mathrm{L}$ of PBS, dried, and stained with $150 \mu \mathrm{L}$ of $0.1 \%$ (vol/vol) crystal violet (Sigma-Aldrich Chemical Co.) for 10 min. Excess crystal violet was removed by washing the plates under running tap water, bound crystal violet was solubilized in $200 \mu \mathrm{L}$ ethanol-acetone $(4: 1, \mathrm{vol} / \mathrm{vol})$, and the absorbance was measured at $590 \mathrm{~nm}$.

Immunofluorescence of LL37. A cryosectioned skin biopsy obtained from a lesion of ET was fixed in $2 \%$ buffered formaldehyde, blocked, and permeabilized with normal goat serum in PBS with $1 \%$ BSA and $0.1 \%$ saponin. Sections were incubated first with 1:100 rabbit polyclonal antihuman LL37 (Innovagen, Lund, Sweden), and thereafter with Cy3-labeled secondary goat anti-rabbit IgG (Jackson ImmunoResearch Laboratories Inc., West Grow, PA). As a final step, slides were incubated with DAPI (Molecular Probes, Eugene, OR), washed, and mounted with Shandon Immu-Mount (Thermo Electron Corporation, Pittsburgh, PA). Confocal images were recorded with a Zeiss 510 META confocal microscope, using $10 \times / 0.3 \mathrm{NA}$ and $5 \times / 0.16 \mathrm{NA}$

Table 1. Oligonucleotide primers used for PCR amplification of the aap gene

\begin{tabular}{ccc}
\hline Primer no. & Primer name & \multicolumn{1}{c}{ Sequence $\left(5^{\prime}-3^{\prime}\right)$} \\
\hline 1 & aap-1 & TGC GAC AAA TTT AAC GAG ATA \\
2 & aap-2 & CCA CTT GCG TAT GTA CCA CTA \\
3 & aap-3 & AGG TGC ACC AGA ACA ACC A \\
4 & aap-4 & CGA CGA CCA AAT ATG AAC AA \\
\hline
\end{tabular}



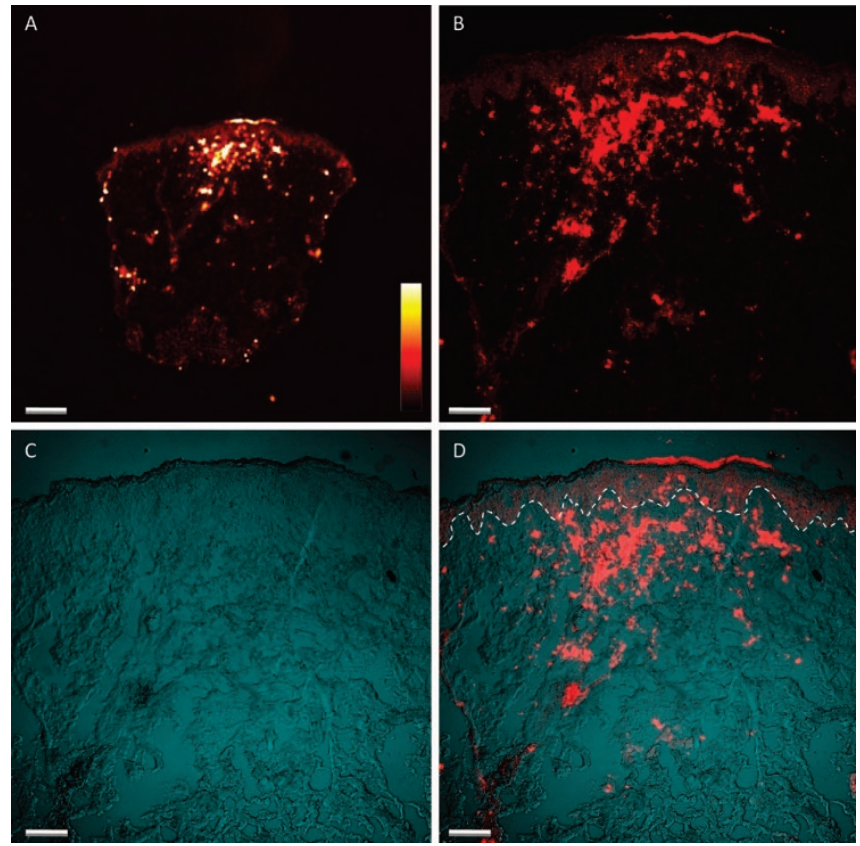

Figure 1. Combined confocal and DIC wide field micrographs of a section from an erythema toxicum lesion. A strong immunosignal of cathelicidin antimicrobial peptide LL37 reaches all the way up to the skin level. Note in the low magnification image $(A)$ the weak but homogeneous peptide expression in the whole epidermal layer. In higher magnification $(B)$, numerous scattered cells with different degree of peptide expression in the dermis can be identified. As a reference, the DIC wide field image is shown in $(C)$ and the combined DIC and confocal image in $(D)$. The border between epidermis and dermis is marked with a white dotted line. The color scale used is a glow scale ranging from white for the strongest immune signals via yellow to dark red for the weakest (color bar inset). Bar: $A, 200 \mu \mathrm{m} ; B-D, 100 \mu \mathrm{m}$.

objectives. Cy3 fluorescence was detected by excitation at $543 \mathrm{~nm}$, with long pass $560 \mathrm{~nm}$ detection. DAPI fluorescence of nuclei was in some images used as a reference, detected by excitation at $405 \mathrm{~nm}$ with a $420-480 \mathrm{~nm}$ band pass filter (not shown in Fig. 1). Controls for autofluorescence and unspecific binding were performed by excluding the primary antibody.

\section{RESULTS}

Antimicrobial activity of LL37 on S. epidermidis. MICs ranged between 8 and $32 \mathrm{mg} \cdot \mathrm{L}^{-1}$ (Table 2). No major differences, as to bacterial susceptibility to LL37, could be observed between the reference strains $(n=4)$ and the CIs $(n=13)$.

Transmission EM. We found that all $(n=13)$ CIs of $S$. epidermidis expressed pilus-like appendages, and that no such structures were found on either of the two laboratory strains (ATCC 12228; ATCC 35984). The appearance of these structures was very similar between the individual strains.

We visualized two different types of pilus-like structures, one appearing with long pilus-like protrusions growing outward from the bacterial cell surface, often in the direction toward another bacteria (Fig. $2 A$ and $B$ ). This type was more commonly seen on bacteria grown on agar plates, although it was also frequently found on bacteria grown in BHI broth.

The other type of structure consisted of a bundle of short fibrils localized on the cell surface, projecting away from the cell wall (Fig. $2 C-F$ ). Bacterial cells were often located in clusters of 3-6 bacteria, where the centrally located cell most often lacked these appendages, whereas the outer cells ex-
Table 2. Antimicrobial activity (MIC in $\mathrm{mg} \cdot \mathrm{mL}^{-1}$ ) of cathelicidin peptide LL37 against 13 CI of $\mathrm{S}$. epidermidis and four reference strains

\begin{tabular}{llc}
\hline \multicolumn{1}{c}{ Isolate } & \multicolumn{1}{c}{ Clinical data } & MIC $\left(\mathrm{mg} \cdot \mathrm{L}^{-1}\right)$ \\
\hline E. coli ATCC 25922 & Reference strain & 8 \\
S. aureus ATCC 29213 & Reference strain & 16 \\
S. epidermidis ATCC 35984 & Reference strain & 32 \\
S. epidermidis ATCC 12228 & Reference strain & 8 \\
CI-1 & Unaffected skin & 32 \\
CI-2 & Unaffected skin & 32 \\
CI-3 & Unaffected skin & 32 \\
CI-4 & Unaffected skin & 16 \\
CI-5 & Unaffected skin & 32 \\
CI-6 & Unaffected skin & 32 \\
CI-7 & Unaffected skin & 16 \\
CI-8 & Unaffected skin & 32 \\
CI-9 & Erythema toxicum & 16 \\
CI-10 & Erythema toxicum & 16 \\
CI-11 & Erythema toxicum & 32 \\
CI-12 & Erythema toxicum & 8 \\
CI-13 & Sepsis & 32 \\
\hline
\end{tabular}

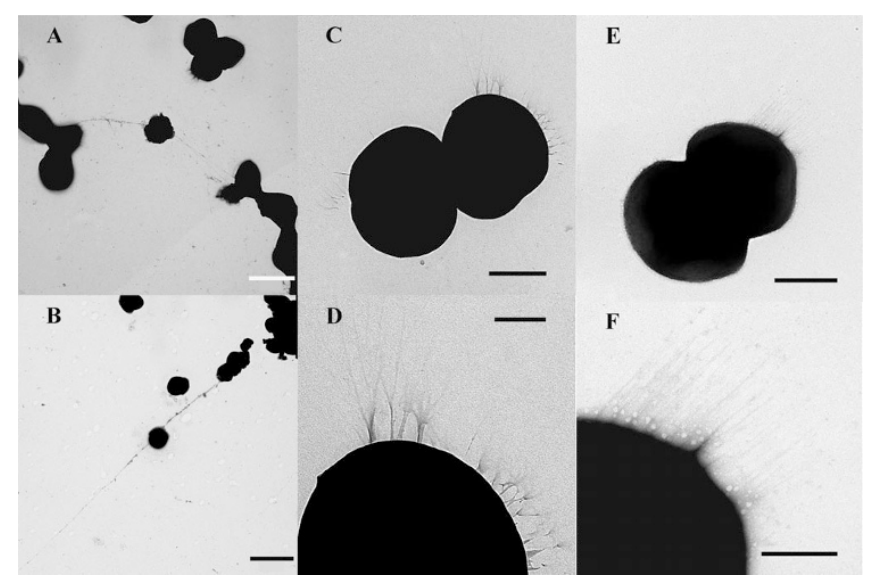

Figure 2. Negative staining transmission EM showing S. epidermidis isolated from the skin of healthy newborn infants. Long fiber-like structures protruding from one cell to another ( $A$ and $B$, from unaffected skin) and typical short pilus-like structures ( $C$ and $D$, from unaffected skin; $E$ and $F$, from an erythema toxicum lesion). Bar: $A, 1 \mu \mathrm{m} ; B, 2 \mu \mathrm{m} ; C, 0.5 \mu \mathrm{m} ; D, 0.2$ $\mu \mathrm{m} ; E, 0.5 \mu \mathrm{m}$; and $F, 0.2 \mu \mathrm{m}$.

pressed pilus-like structures projecting away from the other cells. The length of the appendages was $250-300 \mathrm{~nm}$ as measured from the fibril base to the fibril tip, and the thickness was approximately $2 \mathrm{~nm}$. By screening samples randomly, looking at at least 100 cells, we estimated that $2 / 3$ of the bacteria expressed these pilus-like structures.

Treatment of S. epidermidis with proteinase K completely removed all pilus-like structures as detected by negative staining (data not shown), indicating that these were either comprised of protein or attached to the cell surface by a protein component. Treatment of $S$. epidermidis with DNAase did not change the appearance of the pilus-like structures, as detected by negative staining (data not shown).

Immunogold EM. After incubation of staphylococcal cells with Fbe antibody, the morphologic appearance is suggestive of a possible association of gold particles with the pilus-like structures (Fig. 3).

PCR amplification of the aap gene. The PCR assay was carried out to screen for a 632 base pair (bp) fragment of the 


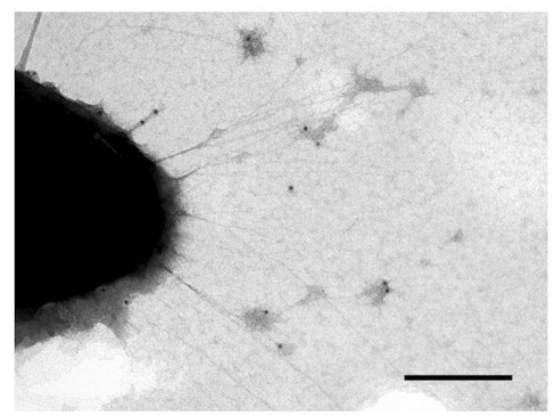

Figure 3. Micrograph showing distribution of gold particles labeled with Fbe antibody on the cell surface of $S$. epidermidis isolated from neonatal skin (CI-9). Bacteria are counterstained with uranyl acetate. Bar: $0.2 \mu \mathrm{m}$.

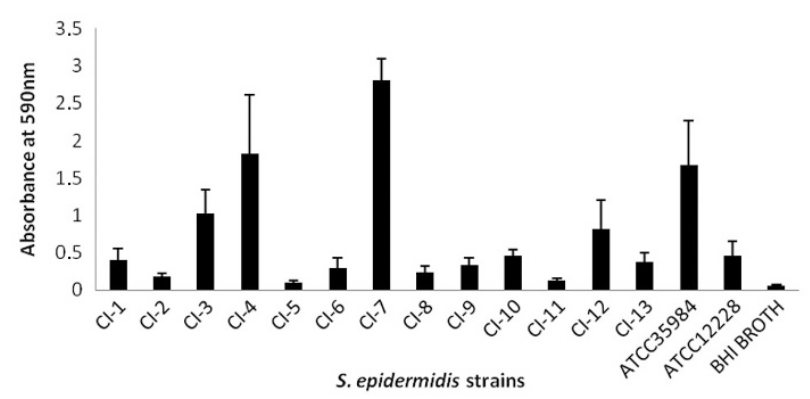

Figure 4. Biofilm formation of S. epidermidis stained with $0.1 \%$ crystal violet. Increased absorbance equates with increased biofilm formation. Results are shown with the CI-1-13, and the reference strains ATCC 35984 and ATCC 12228. Bars and error bars represent the mean \pm SD of results in five replicates of three independent experiments.

A region of aap (nucleotides 1140-1772) and a 149 bp fragment (nucleotides 7023-7172) at the $\mathrm{C}$ terminus of aap. ATCC 35984, ATCC 12228, and the CIs 1-7, 10, 12, 13 gave amplicons of $632 \mathrm{bp}$ and $149 \mathrm{bp}$, respectively (data not shown). It can be deduced that these 12 strains carry the aap gene. For the CI-9, only the $149 \mathrm{bp}$ amplicon was detected (data not shown), and no PCR amplicons were detected for the CI-8 and CI-11 (data not shown). The aligned regions of the DNA sequences of the A region of aap and the $\mathrm{C}$ terminus of aap shared $100 \%$ identity (data not shown).

Assessment of biofilm-forming ability. When comparing the biofilm-forming ability of the different strains, we found that only four of 13 CIs were strong producers of biofilm, as was the S. epidermidis ATCC 35984 used as a positive control. For S. epidermidis strain ATCC 12228 and nine of 13 CIs showed no or limited signs of biofilm-forming ability (Fig. 4).

Immunofluorescence of $\boldsymbol{L L 3 7}$. There was a positive staining of antimicrobial peptide LL37 throughout the entire epidermal layer, and a dense nodular expression was noted in the dermal layer reaching all the way up to the skin surface (Fig. 1).

\section{DISCUSSION}

This study shows that human cathelicidin antimicrobial peptide LL37 significantly inhibits growth of S. epidermidis isolated from the skin of newborn infants. We also found that these bacterial strains commonly express two kinds of pilus- like structures clearly distinct from each other as visualized by EM technique, a feature independent of biofilm-mediated virulence mechanisms. An association of these structures with S. epidermidis surface protein Fbe is suggested.

Commensal colonization of the skin is not unrestricted. The inhibitory mechanisms to limit bacterial growth and protect against assault is partly mediated by the presence of bactericidal peptide or proteins in the skin that includes defensins, lysosome, psoriasin, and LL37 (24). These substances are up-regulated at birth (6), particularly in the rash of erythema toxicum where a substantial accumulation of LL37 expressing cells also occurs (Fig. 1). A comparison of our documented MIC values against estimated local concentrations of LL37 in patients with psoriasis (25) or rosacea (26), reaching skin tissue levels up to approximately $7200 \mathrm{mg} \cdot \mathrm{L}^{-1}(1600 \mu \mathrm{M})$, strongly indicates a significant antimicrobial activity of LL37 on $S$. epidermidis. The use of refined MHB diluted with standard MHB may also have lead to a certain underestimation of the activity of the peptide. Most probably, the constitutive expression of LL37 in the newborn infant is an important factor in regulating the establishment of commensal bacteria at birth.

The shorter pilus-like protrusions that we describe are similar in appearance and positioning not only to the fibrillar structures identified on S. epidermidis ATCC14990 (9), but also to those described in our previous EM studies on neonatal skin (3). The longer pilus-like structures, that seem to interconnect different bacteria to each other, are similar to the appendages described on $S$. epidermidis isolated from human adult blood $(11,12)$. The function of these two different types of cell surface protrusions can only be speculated upon. The shorter pilus-like appendages may be communication structures by which bacteria talk to the host's epidermal keratinocytes in a similar way that occurs in the mammalian intestine, where dendritic cells extend dendrites across tight junctions between intestinal epithelial cells to directly contact bacteria in the lumen (27). A similar picture has been found in the skin of the newborn where the dendritic cell's dendrites reach up to the skin surface (28). The longer filament interconnection of different bacterial cells may express a communication in between these cells.

As illustrated in Figure 3, it appears that Fbe is present in the pilus-like structures, although additional proteins probably are included as well. The exact binding site of surface protein Fbe is unknown, but it contains a sortase recognition sequence of LPXTG used for covalent linkage to bacterial peptidoglycan (18), which we know from other Gram-positive bacteria to be of importance for the assembly of pilus structures $(13,14)$. Fbe is present in most strains of $S$. epidermidis with an equal distribution in invasive and commensal isolates $(29,30)$, similar to what we describe for pilus-like structures.

Aap is a cell wall-anchored protein, prevalent in CIs of $S$. epidermidis. In the previous study on ATCC 14990, it was proposed that each fibril resembles the full-length Aap protein. In our study, we could not detect any amplicons of the aap gene in two of the CIs, and only one of the bp amplicons was detected in one of the isolates. This may indicate that those 
strains have truncated aap genes, or possibly that two of them even lack the aap gene.

In conclusion, this study shows that pilus-like structures are very commonly expressed on $S$. epidermidis isolated from newborns and that these seem to be comprised in part by surface protein Fbe. We also demonstrate that $S$. epidermidis is susceptible to antimicrobial peptide LL37, constitutively expressed in the complex skin barrier of the newborn.

Acknowledgment. We thank Johannes Ries, PhD, Department of Bacteriology, Swedish Institute for Infectious Disease Control, Stockholm, Sweden for excellent laboratory advice.

\section{REFERENCES}

1. Roth RR, James WD 1988 Microbial ecology of the skin. Annu Rev Microbiol 42:441-464

2. Keyworth N, Millar MR, Holland KT 1992 Development of cutaneous microflora in premature neonates. Arch Dis Child 67:797-801

3. Marchini G, Nelson A, Edner J, Lonne-Rahm S, Stavreus-Evers A, Hultenby K 2005 Erythema toxicum neonatorum is an innate immune response to commensal microbes penetrated into the skin of the newborn infant. Pediatr Res 58:613-616

4. Bearman GM, Wenzel RP 2005 Bacteremias: a leading cause of death. Arch Med Res 36:646-659

5. Strunk T, Richmond P, Simmer K, Currie A, Levy O, Burgner D 2007 Neonatal immune responses to coagulase-negative staphylococci. Curr Opin Infect Dis 20:370-375

6. Marchini G, Lindow S, Brismar H, Stabi B, Berggren V, Ulfgren AK, Lonne-Rahm S, Agerberth B, Gudmundsson GH 2002 The newborn infant is protected by an innate antimicrobial barrier: peptide antibiotics are present in the skin and vernix caseosa. Br J Dermatol 147:1127-1134

7. Putsep K, Carlsson G, Boman HG, Andersson M 2002 Deficiency of antibacterial peptides in patients with morbus Kostmann: an observation study. Lancet 360:11441149

8. Radek K, Gallo R 2007 Antimicrobial peptides: natural effectors of the innate immune system. Semin Immunopathol 29:27-43

9. Banner MA, Cunniffe JG, Macintosh RL, Foster TJ, Rohde H, Mack D, Hoyes E, Derrick J, Upton M, Handley PS 2007 Localized tufts of fibrils on Staphylococcus epidermidis NCTC 11047 are comprised of the accumulation-associated protein. J Bacteriol 189:2793-2804

10. Burriel AR 1998 In vivo presence of capsular polysaccharide in coagulase-negative staphylococci of ovine origin. New Microbiol 21:49-54

11. Timmerman CP, Fleer A, Besnier JM, De Graaf L, Cremers F, Verhoef J 1991 Characterization of a proteinaceous adhesin of Staphylococcus epidermidis which mediates attachment to polystyrene. Infect Immun 59:4187-4192

12. Veenstra GJ, Cremers FF, van Dijk H, Fleer A 1996 Ultrastructural organization and regulation of a biomaterial adhesin of Staphylococcus epidermidis. J Bacteriol 178:537-541
13. Scott JR, Zahner D 2006 Pili with strong attachments: Gram-positive bacteria do it differently. Mol Microbiol 62:320-330

14. Telford JL, Barocchi MA, Margarit I, Rappuoli R, Grandi G 2006 Pili in grampositive pathogens. Nat Rev Microbiol 4:509-519

15. Otto M 2004 Virulence factors of the coagulase-negative staphylococci. Front Biosci 9:841-863

16. Vuong C, Otto M 2002 Staphylococcus epidermidis infections. Microbes Infect 4:481-489

17. Hartford O, O’Brien L, Schofield K, Wells J, Foster TJ 2001 The Fbe (SdrG) protein of Staphylococcus epidermidis HB promotes bacterial adherence to fibrinogen. Microbiology 147:2545-2552

18. Nilsson M, Frykberg L, Flock JI, Pei L, Lindberg M, Guss B 1998 A fibrinogenbinding protein of Staphylococcus epidermidis. Infect Immun 66:2666-2673

19. Pei L, Flock JI 2001 Lack of fbe, the gene for a fibrinogen-binding protein from Staphylococcus epidermidis, reduces its adherence to fibrinogen coated surfaces. Microb Pathog 31:185-193

20. Hussain M, Herrmann M, von Eiff C, Perdreau-Remington F, Peters G 1997 A 140-kilodalton extracellular protein is essential for the accumulation of Staphylococcus epidermidis strains on surfaces. Infect Immun 65:519-524

21. The Clinical and Laboratory Standards Institute (CLSI) 2008 Performance Standards for Antimicrobial Susceptibility Testing; 18th Informational Supplement. Clinical and Laboratory Standards Institute, Wayne, PA

22. Dudal S, Turriere C, Bessoles S, Fontes P, Sanchez F, Liautard J, Liautard JP, Lafont V 2006 Release of LL-37 by activated human Vgamma9Vdelta2 T cells: a microbicidal weapon against Brucella suis. J Immunol 177:5533-5539

23. Turner J, Cho Y, Dinh NN, Waring AJ, Lehrer RI 1998 Activities of LL-37, a cathelin-associated antimicrobial peptide of human neutrophils. Antimicrob Agents Chemother 42:2206-2214

24. Niyonsaba F, Ogawa H 2005 Protective roles of the skin against infection: implication of naturally occurring human antimicrobial agents beta-defensins, cathelicidin LL-37 and lysozyme. J Dermatol Sci 40:157-168

25. Ong PY, Ohtake T, Brandt C, Strickland I, Boguniewicz M, Ganz T, Gallo RL, Leung DY 2002 Endogenous antimicrobial peptides and skin infections in atopic dermatitis. N Engl J Med 347:1151-1160

26. Yamasaki K, Di Nardo A, Bardan A, Murakami M, Ohtake T, Coda A, Dorschner RA, Bonnart C, Descargues P, Hovnanian A, Morhenn VB, Gallo RL 2007 Increased serine protease activity and cathelicidin promotes skin inflammation in rosacea. Nat Med 13:975-980

27. Rescigno M, Urbano M, Valzasina B, Francolini M, Rotta G, Bonasio R, Granucci F, Kraehenbuhl JP, Ricciardi-Castagnoli P 2001 Dendritic cells express tight junction proteins and penetrate gut epithelial monolayers to sample bacteria. Nat Immunol 2:361-367

28. Marchini G, Ulfgren AK, Lore K, Stabi B, Berggren V, Lonne-Rahm S 2001 Erythema toxicum neonatorum: an immunohistochemical analysis. Pediatr Dermatol 18:177-187

29. Bradford R, Abdul Manan R, Daley AJ, Pearce C, Ramalingam A, D'Mello D, Mueller Y, Uahwatanasakul W, Qu Y, Grando D, Garland S, Deighton M 2006 Coagulase-negative staphylococci in very-low-birth-weight infants: inability of genetic markers to distinguish invasive strains from blood culture contaminants. Eur J Clin Microbiol Infect Dis 25:283-290

30. Rohde H, Kalitzky M, Kroger N, Scherpe S, Horstkotte MA, Knobloch JK, Zander AR, Mack D 2004 Detection of virulence-associated genes not useful for discriminating between invasive and commensal Staphylococcus epidermidis strains from a bone marrow transplant unit. J Clin Microbiol 42:5614-5619 